\title{
Hurdles in quality neonatal health care provision in an urban city of India: Providers' perspective - A cross sectional study
}

\author{
*Saikiran Deshabhotla ${ }^{1}$, Abhay Singh ${ }^{1}$, Sumeer AliKhan ${ }^{1}$, Baswaraj Tandur $^{1}$
}

Sri Lanka Journal of Child Health, 2021; 50(2): 228-232

\begin{abstract}
Background: Improving the quality of neonatal intensive care should be an important health policy priority. A formal assessment of barriers and priorities for quality improvement has not been undertaken.
\end{abstract}

Objectives: To identify various barriers in the neonatal intensive care unit (NICU) hindering the provision of quality neonatal care as identified by clinicians working in the NICU.

Study population: Doctors working in the Level 2 and Level 3 NICUs, Hyderabad.

Study duration: One year from November 2018 to November 2019.

Study design: Cross-sectional study

Method: Questionnaires were distributed to each eligible clinician working in level 2 and level 3 NICUs. Completed questionnaires were collected back within one week.

Results: Most of the respondents identified family inability to pay $(63,83 \%)$, lack of health insurance $(52,68 \%)$ as the principal barriers to quality health care provision. Poor remuneration $(35,46 \%)$ and team member burnout were pointed out as institutional barriers to quality care.

Conclusions: In this study, clinicians identified family inability to pay and lack of health insurance as the principal clinical barriers to quality health care provision. They also identified poor remuneration and team member burnout as the principal institutional barriers to quality care.

1Princess Durru Shehvar Children's Hospital,
Hyderabad, India
${ }^{* C o r r e s p o n d e n c e: ~ d r s a i 17 @ g m a i l . c o m ~}$

https://orcid.org/0000-0002-4592-7577

(Received on 01 May 2020: Accepted after revision on 19 June 2020)

The authors declare that there are no conflicts of interest

Personal funding was used for the project.

Open Access Article published under the Creative

Commons Attribution CC-BY (c) (i) License
DOI: http://dx.doi.org/10.4038/sljch.v50i2.9560

(Key words: Neonatal care, quality improvement, NICU, hurdles, priorities, cross-sectional study)

\section{Introduction}

A systematic analysis of global, regional and national causes of child mortality in 2013 identified preterm birth and infections to be the two major causes of neonatal deaths ${ }^{1}$. These conditions are amenable to improvement in the quality and safety of care delivered to high-risk newborns in the neonatal intensive care unit (NICU) settings. The study setting in Hyderabad, India, has $60 \%$ of neonatal health care provided by the private sector, where $80 \%$ of the population bears the cost of medical care out of their pocket. There are 10 major paediatric hospitals in the private sector and two large government hospitals in the public sector. Only a small proportion of the population is covered by government or private insurers. Currently there is a recent interest in quality assessment, assurance, and improvement in health care. Barriers to quality improvement of neonatal intensive care is an under-researched area. Quality of neonatal intensive care can be improved once the barriers are identified. Quality improvement (QI) focus will help not only in the reduction of neonatal mortality but also better utilization of scarce monetary and human resources.

\section{Objectives}

To identify various barriers in the neonatal intensive care unit (NICU) hindering the provision of quality neonatal care as identified by clinicians working in the NICU.

\section{Method}

This cross-sectional survey was done over a year from June 2018 to June 2019, among the physicians working in Level II and Level III NICU and having a work experience of more than one year. All physicians working in the NICU of paediatric hospitals of Hyderabad represented the study population. The data collection tool was a self-reported questionnaire The team of investigators developed the questionnaire based on existing instruments and an earlier study ${ }^{2,3,4}$. The questionnaire was designed to collect information of respondents regarding clinical and institutional barriers for quality neonatal care. The clinical barriers were identified to suggest possible 
socioeconomic factors for poor quality of medical care, whereas the institutional barriers were selected to identify human resource barriers to quality care. The five-point Likert scale was the predominant response scale. A convenient sample size of 100 was calculated to have a normal distribution of responses and incorporating finite correction.

Ethical issues: Ethical clearance was obtained from the Human Ethics Committee of Princess Durru Shehvar Children's \& General Hospital, Hyderabad, India (No. 131-46136-162-209804) in November 2018. Participants were assured that participation in the survey was voluntary and that their responses would be kept confidential.

Statistical analysis: Data were analysed using SPSS version 20 (IBM, Armonk, N.Y., USA) using appropriate statistical tests.

\section{Results}

A total of 100 questionnaires were distributed amongst eligible paediatricians and neonatologists, working in the NICUs of major paediatric hospitals of the city of Hyderabad. We had a response rate of $76 \%$. Of the 44 major hospitals surveyed 29 (66\%) were in the private sector and $34(77 \%)$ institutes were running academic courses. (Figure 1).

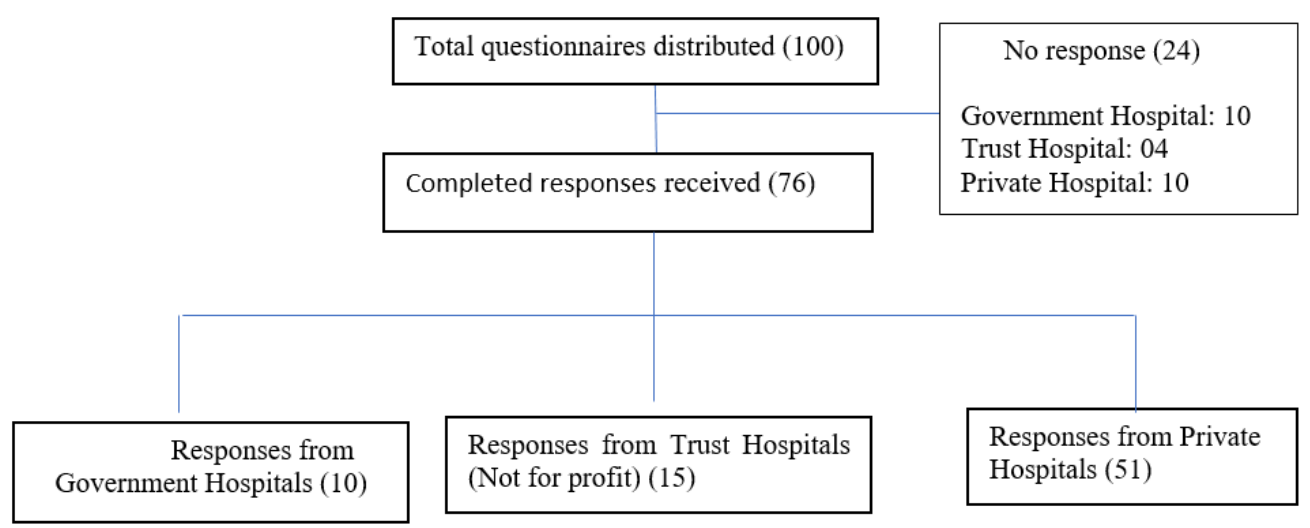

\section{Demographic profile}

Of the 76 health care providers who successfully submitted the survey form, $60 \quad(79 \%)$ were consultants and $16(21 \%)$ were clinical registrars. Regarding professional education, 54 (72\%) were holding postgraduate degrees and $22(28 \%)$ had neonatology subspecialty training. The median work experience was 3 years (IQR 1-6).

In our survey $36(47 \%)$ and $28(37 \%)$ of the respondents strongly felt that family inability to
Figure 1

bear health care cost and lack of health insurance respectively were the major barriers in the provision of quality health care. Twenty six (34\%) and $21(27 \%)$ strongly felt that lack of adequate nursing and lack of ancillary staff (lactational counselor, physiotherapist, social health worker) respectively were the barriers for effective clinical care. Table 1 shows the major clinical barriers as agreed and disagreed by the respondents of the survey.

Table 1: Barriers to delivery of quality clinical care

\begin{tabular}{|c|c|c|c|c|c|}
\hline Clinical barrier & $\begin{array}{c}\text { Strongly agree } \\
\mathrm{n}(\%)\end{array}$ & $\begin{array}{l}\text { Agree } \\
\text { n (\%) }\end{array}$ & $\begin{array}{l}\text { Neutral } \\
\text { n }(\%)\end{array}$ & $\begin{array}{c}\text { Disagree } \\
\text { n }(\%)\end{array}$ & $\begin{array}{c}\text { Strongly disagree } \\
\text { n }(\%)\end{array}$ \\
\hline Family inability to bear health care costs & $36(47)$ & $27(36)$ & $08(10)$ & $04(05)$ & $01(02)$ \\
\hline Lack of health insurance for the family & $28(37)$ & $24(32)$ & $14(18)$ & $10(13)$ & $0(0)$ \\
\hline Lack of adequate nursing availability & $26(34)$ & $23(30)$ & $07(09)$ & $19(25)$ & $01(02)$ \\
\hline $\begin{array}{l}\text { Lack of ancillary staff availability (physiotherapist/ } \\
\text { lactational counselor/ audiologist) }\end{array}$ & $21(27)$ & $25(33)$ & $15(20)$ & $14(18)$ & $01(02)$ \\
\hline Lack of nursing training & $20(26)$ & $26(34)$ & $11(15)$ & $17(22)$ & $02(3)$ \\
\hline Lack of health awareness among the parents & $14(18)$ & $35(46)$ & $15(20)$ & $12(16)$ & $0(0)$ \\
\hline $\begin{array}{l}\text { Lack of subspecialty care (paediatric cardiologist / } \\
\text { neurologist/ Others) }\end{array}$ & $13(17)$ & $16(21)$ & $12(16)$ & $23(30)$ & $12(16)$ \\
\hline Absent protocol-based guidelines & $11(14)$ & $21(28)$ & $11(14)$ & $22(30)$ & $11(14)$ \\
\hline Lack of proper neonatal transport & $11(14)$ & $31(41)$ & $06(08)$ & $18(24)$ & $10(13)$ \\
\hline Lack of sufficient equipment & $07(09)$ & $21(28)$ & $14(19)$ & $26(34)$ & $08(10)$ \\
\hline
\end{tabular}

In our study, almost half of the respondents strongly felt that there was a lack of teamwork culture in their respective work units and nearly one-third of the respondents strongly felt that burnout and poor motivation among team members was a hindrance to quality neonatal care. Table 2 shows the institutional barriers to providing quality neonatal care in the NICU. 
Table 2: Institutional factors identified as barriers for providing quality care in neonatal intensive care unit

\begin{tabular}{|l|c|c|c|c|c|}
\hline \multicolumn{1}{|c|}{ Institutional barrier } & $\begin{array}{c}\text { Strongly agree } \\
\mathbf{n}(\mathbf{\%})\end{array}$ & $\begin{array}{c}\text { Agree } \\
\mathbf{n}(\mathbf{\%})\end{array}$ & $\begin{array}{c}\text { Neutral } \\
\mathbf{n}(\mathbf{\%})\end{array}$ & $\begin{array}{c}\text { Disagree } \\
\mathbf{n}(\mathbf{\%})\end{array}$ & $\begin{array}{c}\text { Strongly disagree } \\
\mathbf{n}(\mathbf{\%})\end{array}$ \\
\hline Lack of good teamwork & $34(45)$ & $33(43)$ & $03(04)$ & $05(06)$ & $01(02)$ \\
\hline Burnout and poor motivation in team & $26(34)$ & $18(24)$ & $10(13)$ & $14(18)$ & $08(10)$ \\
\hline Lack of support for clinical research & $19(25)$ & $26(34)$ & $07(09)$ & $17(22)$ & $07(09)$ \\
\hline $\begin{array}{l}\text { Lack of institutional support in knowledge upgrade } \\
\text { (attending conferences, training workshops) }\end{array}$ & $08(10)$ & $18(24)$ & $13(17)$ & $34(45)$ & $03(04)$ \\
\hline
\end{tabular}

\section{Discussion}

In one of its kind studies from India, we tried to elucidate the factors hindering the delivery of quality neonatal health care. Quality services will not only improve the mortality and morbidity rates but will also decrease the trust deficit between patient and clinician which is the need of the hour. In the present study, financial constraints and lack of health insurance are identified as major factors in not being able to access quality health care facilities In India, where nearly two-thirds of healthcare provision is by the private sector, majority of the recipients pay out of pocket ${ }^{5,6}$. In a study from Mexico, Weiss et al reported that the principal barriers in neonatal care were family inability to pay and insufficient financial reimbursement ${ }^{3}$.

Financial constraints in the low and middle countries are difficult to overcome without substantial socioeconomic improvement, increased per capita health-care expenditure and systematic change in health-care delivery ${ }^{7}$. There is a need to promote private and local or federal government partnerships in promoting the delivery of quality neonatal care ${ }^{8}$. The introduction of health care insurance for the poor is an important step by the government of India. Providing universal health coverage and covering all citizens under national health insurance is a social intervention.

Recently, the Indian Government launched the world's largest Government-funded health care programme providing comprehensive health care to neonates from the lower socio-economic strata ${ }^{10}$. Beneficiaries can avail of benefits in both public and empaneled private facilities and entitled families can use the quality health services they need without facing financial hardships. This is a positive step towards advancing the agenda of Universal Health Coverage (UHC). Over the next few years, it needs to be assessed how national health insurance will impact on neonatal and maternal health care $^{11}$. Cost-effectiveness analysis is also the need of the hour. Do the benefits of the neonatal intervention (increased survival of babies) outweigh the costs of neonatal care and long-term care for survivors with disabilities? ${ }^{12}$.

There is a strong association between nursing staff to patient ratio and delivery of safe health care. In this study, the unavailability of adequately trained nursing and the ancillary staff was identified as an important barrier in providing quality care. To address this shortfall, both enhanced recruitment and minimizing attrition of nursing care is important. The following areas in neonatal nursing need to be focused on like standardizing neonatal nursing education modules, creating specialist neonatal nurses with skills and knowledge and neonatal nurses' empowerment in handling clinical emergencies $^{13}$. Very few respondents felt a lack of infrastructure as the hindrance for quality care, possibly due to the majority of them working in the private sector

In this study, when clinicians were asked regarding management factors responsible for poor neonatal care quality, the majority of respondents identified lack of proper teamwork and burnout among team members as major reasons. In an earlier study burnout and poor motivation were very widespread among professionals working in the $\mathrm{NICU}^{14}$. The medical profession demands much higher commitment, knowledge, skills, competence and accountability. Compassionate and dedicated professionals working in the NICU improve outcomes not only for babies but also for their families ${ }^{15}$. Organization's work culture and ethics alongside individual-level interventions effectively prevent burnout.

Clinical research is the backbone of medical science evolution. It provides the opportunity to find better therapies and treatment strategies to improve patient care. The goal of research is to improve the quality of care and outcome of babies. Neonatology is a very young branch and is a constantly evolving science. In our study, the majority of respondents felt that there is a lack of support for clinical research from hospitals. To meet this challenge, better funding practices are needed and providing clinicians with time for research activities must be ensured.

A quarter of the respondents strongly agreed that lack of opportunities towards clinical research was a barrier towards quality care. Clinical research and collaboration are critical to generating high quality, reliable, and statistically sound data, which help in identifying problems and enables an objective assessment of whether change and improvement have indeed occurred. Like in many western countries quality networks should be formed to 
improve clinical research ${ }^{16}$. To deliver quality neonatal health care there needs to be a joint effort of socioeconomic measures like enhanced health coverage and institutional efforts to improve teamwork. There is a need for further studies with appropriate study designs to test this postulate.

The limitations of the study are that it is a small sample survey, there were not enough responses from government hospitals and parents' perceptions of barriers in accessing neonatal care were not evaluated.

\section{Conclusions}

In this study, clinicians identified family inability to pay and lack of health insurance as the principal clinical barriers to quality health care provision. They also identified poor remuneration and team member burnout as the principal institutional barriers to quality care.

\section{References}

1. Martinez A, Khu D, Boo NY, Neou L, Bounnack S, Partridge J. Barriers to neonatal care in developing countries: Parents' and providers' perceptions. Journal of Paediatrics and Child Health 2012; 48: 852-8.

https://doi.org/10.1111/j.14401754.2012.0 2544.x

PMid: 22970681

2. Boukus E, Cassil A, O’Malley AS. A snapshot of U.S. physicians: key findings from the 2008 Health Tracking Physician Survey. Data Bulletin (Centre for Studying Health System Change) 2009; 35:1-11.

3. Weiss K, Kowalkowski M, Treviño R, Cabrera-Meza G, Thomas E, Kaplan H, et al. Needs assessment to improve neonatal intensive care in Mexico. Paediatrics and International Child Health 2015; 35(3): 213-9.

https://doi.org/10.1179/2046905515Y.000 0000044

PMid: 26134488

4. Sexton JB, Helmreich RL, Neilands TB, Rowan K, Vella K, Boyden J, et al. The Safety Attitudes Questionnaire: psychometric properties, benchmarking data, and emerging research. BMC Health Services Research 2006; 6:44. https://doi.org/10.1186/1472-6963-6-44 PMid: 16584553 PMCid: PMC1481614
5. Aldana-Valenzuela C. Barriers to improve neonatal care in Mexico. Paediatrics and International Child Health 2016; 36(2):163-163.

https://doi.org/10.1080/20469047.2016.11

54644

PMid: 27116893

6. Keane M, Thakur R. Health care spending and hidden poverty in India. Resource Economics 2018; 72(4): 435-51. https://doi.org/10.2139/ssrn.3118615

7. Reddy KS. Health Care Reforms in India. JAMA 2018; 319(24):2477-8.

https://doi.org/10.1001/jama.2018.5284 PMid: 29800246

8. Gupta A, Fledderjohann J, Reddy H, Raman VR, Stuckler D, Vellakkal S. Barriers and prospects of India's conditional cash transfer program to promote institutional delivery care: a qualitative analysis of the supply-side perspectives. BMC Health Services Research 2018; 18(1):40. https://doi.org/10.1186/s12913-018-28498

PMid: 29370798 PMCid: PMC5785836

9. Government of India. Ayushman Bharat National Health Protection Mission | National Portal of India [Internet]. [cited 2018 Dec 8]. Available from: https://www.india.gov.in/spotlight/ayushm an-bharat-national-health-protectionmission

10. Angell BJ, Prinja S, Gupt A, Jha V, Jan S. The Ayushman Bharat Pradhan Mantri Jan Arogya Yojana and the path to universal health coverage in India: Overcoming the challenges of stewardship and governance. PLOS Medicine 2019; 16(3):e1002759. https://doi.org/10.1371/journal.pmed.1002 759

PMid: 30845199 PMCid: PMC6405049

11. 'Ayushman Bharat' Program and Universal Health Coverage in India [Internet]. [cited 2020 Jan 6]. Available from: https://indianpediatrics.net/june2018/june495-506.htm https://doi.org/10.1007/s13312-018-13411

PMid: 29978817 
12. Profit J, Lee D, Zupancic JA, Papile L, Gutierrez C, Goldie SJ, et al. Clinical benefits, costs, and cost-effectiveness of neonatal intensive care in Mexico. PLoS Medicine 2010; 7(12): e1000379 https://doi.org/10.1371/journal.pmed.1000 379

PMid: 21179496 PMCid: PMC3001895

13. Kalyan G, Vatsa M. Neonatal nursing: An unmet challenge in India. Indian Journal of Pediatrics 2014; 81(11): 1205-11. https://doi.org/10.1007/s12098-014-15674

PMid: 25278279

14. Profit J, Sharek PJ, Amspoker AB, Kowalkowski MA, Nisbet CC, Thomas $\mathrm{EJ}$, et al. Burnout in the NICU setting and its relation to safety culture. BMJ Quality and Safety 2014; 23(10): 806-13. https://doi.org/10.1136/bmjqs-2014002831

PMid: 24742780 PMCid: PMC4167972
15. Tawfik DS, Sexton JB, Kan P, Sharek PJ, Nisbet CC, Rigdon J, et al. Burnout in the neonatal intensive care unit and its relation to healthcare-associated infections. Journal of Perinatology 2017; 37(3):31520.

https://doi.org/10.1038/jp.2016.211 PMid: 27853320 PMCid: PMC5334140

16. Profit J, Soll RF. Neonatal networks: clinical research and quality improvement. Seminars in Fetal and Neonatal Medicine 2015; 20(6):410-5.

https://doi.org/10.1016/j.siny.2015.09.001 PMid: 26453046 